\title{
Studi Pustaka Tentang Kerentanan Keamanan E-Learning dan Penanganannya
}

\author{
Reza Pramudita ${ }^{1}$, Syifaul Fuada ${ }^{2, *}$, Nuur Wachid Abdul Majid ${ }^{3}$ \\ ${ }^{1}$ Fakultas Teknik, Teknik Elektro, Universitas Widyatama, Bandung, Indonesia \\ ${ }^{2}$ Program Studi Sistem Telekomunikasi, Universitas Pendidikan Indonesia, Bandung, Indonesia \\ ${ }^{3}$ Program Studi Pendidikan Sistem dan Teknologi Informasi, Universitas Pendidikan Indonesia, Bandung, Indonesia \\ Email: ${ }^{1}$ rezapramudita@widyatama.ac.id, 2,*Syifaulfuada@upi.edu, ${ }^{3}$ nuurwachid@upi.edu \\ Email Penulis Korespondensi: Syifaulfuada@upi.edu
}

\begin{abstract}
Abstrak-E-learning merupakan media pendidikan yang menggunakan TIK dalam proses pembelajaran. Dewasa ini, beberapa perguruan tinggi di Indonesia telah mengintregasikan perkuliahannya dengan sistem e-learning. Dengan e-Learning, maka pembelajaran dapat dilakukan diluar kelas, kapanpun dan dimanapun. Berdasarkan kajain pustaka, e-learning telah terbukti memiliki banyak dampak positif kepada komponen-komponen dan ekosistem Pendidikan Tinggi, baik mahasiswa, dosen, tenaga Pendidikan, maupun para pejabat kampus. Meskipun menawarkan banyak keuntungan dalam proses belajar dan pembelajaran, seperti teknologi informasi pada umumnya, sistem e-learning juga rentan terhadap ancaman keamanan. Hal ini disebabkan oleh adanya beberapa celah keamanan yang dapat ditembus oleh peretas, dimana data-data yang ada didalam $e$ learning berpotensi besar untuk diintip bahkan dimodivikasi oleh pihak-pihak yang tidak bertanggung jawab. Sehingga aspek keamanan sistem e-learning harus diperhatikan agar Perguruan Tinggi dapat menjalankan bisnis (dalam bidang pendidikan) dengan baik. Makalah ini bertujuan untuk mendeskripsikan tentang $e$-Learning, peluang pemanfaatan, tantangan keamanan, dan beberapa solusi yang pernah ditawarkan. Metode penelitian yang digunakan pada makalah ini adalah studi literatur dari literatur terkini.
\end{abstract}

Kata Kunci: Keamanan Informasi, e-Learning, Kerentanan

\begin{abstract}
E-learning is an educational media that use ICT in the learning process. Nowadays, most of the higher education (universities) in Indonesia have integrated the learning process with e-learning systems. By using this system, learning can be done outside the classroom, anytime and anywhere. Based on the literature reviews, e-learning has many positive impacts on higher education components and its ecosystems, i.e., students, lecturers, higher education staff, and campus officials. Although it offers many advantages, similar to the information technology in general, e-learning systems are also vulnerable to security issues. Because, several security holes in the system can be penetrated easily by hackers, where the essential data contained in e-learning has high potential to be spoofed even modified by irresponsible parties. The security aspect of the e-learning system must be considered to minimize risks. Thus, the higher education can run their business as well. This paper aims to elaborate on the e-Learning system, opportunities, challenges, and several offered solutions on it. The research method used in this paper is literature studies from the latest references.
\end{abstract}

Keywords: Information Security, e-Learning, Vulnerability

\section{PENDAHULUAN}

Pengembangan sistem pembelajaran semakin hari telah mengalami banyak perubahan, hal ini terjadi salah satunya dilatar belakangi oleh sistem pembelajaran konvensional antara tutor dan peserta didik yang dirasa kurang efisien lagi. Maka dari permasalahan tersebut perlu dilakukan suatu pengembangan yang bertujuan untuk meningkatkan efektifitas pembelajaran, terutama dalam hal alokasi waktu pertemuan antara antara peserta didik dan tutor yang biasanya hanya terjadi di kelas. Salah satu terobosan untuk mengatasi masalah tersebut adalah dengan dihadirkannya sistem pembelajaran berbasis e-learning yang merupakan suatu jenis inovasi belajar mengajar yang memungkinkan tersampaikannya bahan ajar ke peserta didik dengan menggunakan media internet. Sejauh ini, sistem e-learning adalah umum/biasa digunakan oleh para penyelenggara pendidikan terbuka dan jarak jauh. Berdasarkan terbitnya Surat Keputusan Menteri Pendidikan Nasional No.107/U/2001 tentang 'Penyelenggaraan Program PTJJ', maka sistem e-learning ini sudah diizinkan digunakan untuk membantu proses pembelajaran. Sistem $e$-learning menawarkan konsep anytime dan anywhere yang berarti $e$-learning menawarkan pembelajaran kapanpun dan dimanapun dan menghilangkan masalah yang terkait dengan jarak. Selain itu, penggunaan teknologi dalam pembelajaran akan memberikan berbagai keuntungan lain, seperti memperbaiki kualitas pembelajaran, memberikan akses secara signifikan lebih baik untuk pendidikan dan pelatihan, penurunan biaya pendidikan dan membantu itu menjadi lebih hemat biaya.

Namun, meskipun fakta bahwa internet telah menjadi suatu lingkungan dimana informasi dapat diperoleh dengan mudah dan cepat, masih terdapat faktor yang mungkin dapat merugikan, yaitu faktor keamanan pada sistem e-learning [1]. Keamanan dalam suatu sistem tentunya sangat dibutuhkan untuk menjaga integritas data yang terkandung dalam sistem tersebut. Tantangan untuk menjaga integritas data ini muncul setelah sistem tersebut terkoneksi dengan jaringan komputer dan terhubung dengan internet. Integritas dan keamanan data yang tersimpan dalam sistem harus dijaga keasliannya. Sehingga dapat dipastikan bahwa data tersebut tidak dapat dimodifikasi lagi sehingga terjaga keasliannya, kecuali untuk data-data yang memang bersifat fleksibel untuk dimodifikasi. Kepastian bahwa sistem dapat diakses dari manapun juga harus menjadi hal yang diperhatikan, sehingga availability dari sistem dapat terpenuhi. Dengan terkoneksinya sistem ke jaringan komputer dan internet, maka 
peluang berubah atau rusaknya data akan semakin terbuka lebar, karena user dari sistem e-learning yang berpotensi berbahaya (malicious user) akan mudah masuk ke sistem melalui jaringan komputer/internet. S. Mandala dkk [2], melaporkan bahwa peretas sering mencuri data pribadi pengguna untuk dijual kembali. Selain itu perlu diterapkan juga perlindungan konten pada e-learning yang mengacu pada perlindungan integritas dan hak cipta dari materi pelajaran. Sementara perlindungan aplikasi berbasis website sangat diperlukan karena serangan meningkat pesat dalam beberapa tahun terakhir.

Hal ini menjadi tinjauan bersama, mengingat pembelajaran abad 21 juga harus berinteraksi dengan teknologi. Sehingga perlu adanya konsep pembelajaran elektronik yang aman dan dapat digunakan dengan nyaman oleh pengguna. E-learning menjadi bagian sebagai media pembelajaran yang dapat membantu para pengguna untuk meningkatkan kompetensi sesuai dengan target pencapaian. Permasalahan terbesar adalah apabila $e$-learning tersebut tidak aman sehingga data-data terpenting mudah tercuri oleh para peretas.

Paper yang membahas tentang taksonomi penanganan kerentanan e-Learning masih belum ditemukan secara komperhensif. Dengan demikian, perlu adanya kajian yang mendalam berkaitan dengan topik tersebut. Paper ini merupakan kajian pustaka secara umum mendiskusikan mengenai beberapa kerentanan keamanan yang mungkin terjadi pada sistem e-learning, kategorisasi untuk perlindungan e-learning berdasarkan sumber kerentanan, dan beberapa metode atau penanganan yang dapat dilakukan untuk menanggulangi beberapa kerentanan keamanan tersebut. Metode penulisan adalah studi literatur. Paper ini membahas tentang (1) Pengertian dan Kategorisasi dari e-learning; (2) e-learning untuk meningkatkan mutu pendidikan; (3) Perkembangan Fungsionalitas e-learning dan Spesifikasi Ideal; (4) Arsitektur Sistem online e-learning; (5) Standar Keamanan Informasi Pada Sistem e-learning; (6) Ancaman Serangan Pada Sistem e-learning; (7) Penanganan Terhadap Kerentanan Serangan Sistem e-learning; dan (8) Model Penerapan Keamanan Informasi Pada Sistem e-learning.

\section{METODE PENULISAN}

Penelitian ini merupakan jenis penelitian kajian pustaka yang diperoleh/dikaji dari sumber-sumber terpercaya yang berkaitan dengan E-Learning, jenis-jenis serangan pada E-Learning dan cara penanganannya. Tinjauan Pustaka merupakan ringkasan dan sinopsis dari bidang riset tertentu, yang memungkinkan siapapun akan membaca makalah ini untuk dasar teori penelitian eksperimen. Kajian pustaka merupakan hal fundamental mengapa seorang/tim peneliti melakukan penelitian khusus ini [3]. Penulisan paper ini diawali dari minimnya literatur yang merangkum tentang penanganan dari berbagai jenis serangan yang terjadi pada sistem E-learning. Kemudian penulis melakukan review terfokus pada bahasan terkait kemudian melakukan taksonomi penanganan E-learning yang terindikasi mendapatkan serangan dari peretas.

\section{HASIL DAN PEMBAHASAN}

\subsection{E-learning: Pengertian dan Kategorisasi}

Hartley [4] mendefinisikan bahwa e-learning merupakan suatu jenis belajar mengajar yang memungkinkan tersampaikannya bahan ajar ke mahasiswa dengan menggunakan media internet, intranet atau media jaringan komputer lain. Selain itu, J. Kumar [5] mendefinisikan E-learning merupakan pengajaran dan pembelajaran yang menggunakan rangkaian elektronik menyangkut LAN, WAN, atau internet untuk menyampaikan isi pembelajaran, interaksi, atau bimbingan. Sedangkan O.W. Purbo [6] menjelaskan bahwa istilah " $e$ " atau singkatan dari elektronik dalam e-learning digunakan sebagai istilah untuk segala teknologi yang digunakan untuk mendukung usaha-usaha pengajaran lewat teknologi elektronik internet [7]. Merujuk dari beberapa definisi yang dikemukakan beberapa ahli tersebut, maka penulis menyimpulkan bahwa e-learning adalah suatu jenis belajar mengajar yang dapat dilakukan kapanpun dan dimanapun yang menggunakan media elektronik sebagai media pembelajaran.

Berkaitan dengan kategori, S. Mandala, dkk [2] dalam literaturnya membagi e-learning ke dalam dua kategori, yaitu, asynchronous e-learning dan synchronous e-learning.

Dalam asynchronous e-learning, peserta didik dapat log on ke dalam sistem e-learning untuk mengunduh dokumen atau mengirim pesan ke instruktur atau rekan-rekannya setiap saat. E-learning tipe ini umumnya difasilitasi oleh media seperti $e$-mail dan board diskusi untuk mendukung kolaborasi bekerja antara peserta didik dan instruktur meskipun mereka mungkin tidak online pada waktu yang sama. Konsep utama dari $e$-learning ini adalah fleksibel $e$-learning. Dengan sifat ini, kemungkinan akan banyak orang yang memilih kursus online.

Sementara pada synchronous e-learning, peserta didik akan memiliki sesi sinkron dan real-time untuk interaksi langsung antara instruktur. E-learning ini umumnya didukung oleh media seperti video conference dan chatting, dan memungkinkan peserta didik untuk mengembangkan komunitas belajar. Sedangkan T. Ayodele, dkk [6] mengkategorikan e-learning ke dalam empat bidang utama, yakni sebagai berkut

a) Self-Paced Online e-learning: Pada tipe ini, peserta didik dapat mengakses database dari sumber kursus online melalui Intranet atau Internet. Ini adalah bentuk forum, chat room, percakapan e-mail, dan pesan instan. Tipe 
ini sedikit lebih interaktif sebagai media online yang menawarkan kesempatan untuk pertanyaan yang lebih spesifik dan jawaban, serta jawaban yang lebih mendesak.

b) Self-Paced Offline e-learning: Pada tipe ini, peserta didik dapat mengakses sumber belajar seperti database atau computer assisted paket pembelajaran offline (misalkan belajar dari komputer standalone atau melalui hard drive, CD atau DVD).

c) Synchronous Group-based e-learning: Pada tipe ini, pembelajaran dilakukan secara real-time dengan instruktur yang langsung memfasilitasi pembelajaran. Setiap peserta didik dapat mengakses pada waktu yang ditetapkan dan dapat berkomunikasi langsung dengan instruktur. Jenis media memungkinkan peserta didik untuk mengadakan beberapa sesi belajar dan hanya berlangsung melalui situs Internet Website, audio atau video conference, telepon internet atau melalui siaran langsung di ruang kelas.

d) Asynchronous Group-based e-learning: Tipe ini merupakan pembelajaran online yang tidak ditentukan oleh dimana lokasi peserta didik itu berada, dan dimana pertukaran ilmu terjadi dengan penundaan waktu (tidak secara real-time). Contoh umum dari kegiatan semacam ini termasuk diskusi online melalui mali list elektronik dan text-based konferensi dalam belajar sistem manajemen.

\subsection{E-learning untuk Pendidikan dan Peningkatan Mutu Pembelajaran}

Pada dasarnya e-learning disiapkan untuk membantu mahasiswa dalam meningkatkan kompetensi pada saat perkuliahan. Penerapan e-learning menjadi bagian dari langkah untuk menerapkan konsep technology-enabled learning yang sudah banyak digagas oleh para pakar pendidikan dan digadang-gadang sebagai bagian dari pembelajaran abad 21. E-learning menjadi rujukan utama sebagai media pembelajaran bagi para guru untuk membantu dalam menyampaikan materi pembelajaran di kelas maupun di luar kelas. Peningkatan mutu pembelajaran dapat terwujud apabila proses KBM dapat berjalan dengan baik sesuai dengan tujuan pembelajaran [8].

Penggunaan e-learning yang pada awalnya hanya digunakan untuk membantu pembelajaran menggunakan komputer. Pada tahun 2000an [9], penerapan e-learning semakin massive dilakukan, terlebih mengunggah material pembelajaran melalui laman e-learning. Pengembangan e-learning terus dilakukan hingga pada saat ini tidak hanya berfungsi sebagai media pembelajaran saja, namun dapat bekolaborasi dalam pembelajaran. Bentuk kolaborasi tersebut dapat terlihat dengan banyaknya tools yang tersedia untuk mendukung pembelajaran. Tools tersebut antara lain: quiz, forum diskusi, video conferences, bimbingan online, dll. Kelengkapan tools pada $e$ learning disesuaikan dengan kebutuhan pengguna yang saat ini lebih senang dalam penggunaan media sosial [10].

Pengembangan $e$-learning dari masa ke masa ini yang nantinya turut berperan dalam pembelajaran yang diharapkan dapat optimal. Pembelajaran berbantuan teknologi sebagai bagian dari pendidikan 4.0 ini merupakan konsep yang sudah dirancang sejak lama oleh para ahli untuk memberikan stimulus kepada siswanya agar optimal dalam mengakuisisi kompetensi dari guru. Selain itu, penerapan e-learning dapat meningkatkan kemampuan berfikir kritis pada siswa, karena kemampuan berfikir kritis merupakan aspek paling penting dalam pembelajaran [11] [12]. E-learning difungsikan untuk mempermudah akses para pengguna dalam proses pembelajaran, meningkatkan aspek fleksibilitas dalam penggunaannya, dan memudahkan pendidik untuk menampilkan konsepkonsep yang bersifat abstrak [13].

Melalui perkembangan teknologi yang semakin pesat, siswa dapat memanfaatkan kemudahan fasilitas tersebut untuk mengakses ilmu pengetahuan secara luas dan massive. Selain itu, siswa dapat berinteraksi dengan native speaker dan para ahli untuk menanyakan atau menggali informasi terkait materi yang akan dipelajari [14]. Materi tersebut sudah tersedia secara bebas, sehingga para siswa dapat mengakses secara bebas dan luas. Konsep e-learning pada era saat ini lebih banyak memadukan prinsip multimedia, yaitu: (1) memasukkan video rekaman maupun live dari pembicara; (2) dokumen yang dapat diunduh sewaktu-waktu oleh pengguna; (3) audio hasil rekaman para tutor; dan (4) beberapa fasilitas penunjang lainnya untuk interaksi para siswa dan pemateri.

Penerapan e-learning pada pembelajaran dinilai sangat membantu para siswa dalam memperoleh kompetensi yang disyaratkan. Vitoria, dkk., melakukan kajian terkait fungsi e-learning bagi siswa setelah menggunakannya [15]. Hasil penelitian ini menunjukkan bahwa para siswa sangat terbantu dengan adanya $e$ learning dan module yang disediakan sangat mudah digunakan. Hal ini perlu ditekankan bahwa e-learning pada dasarnya harus mudah digunakan dan disesuaikan dengan tingkatan pengguna. Penyesuaian ini sangat berarti karena sistem dapat digunakan oleh pengguna yang mengerti cara menggunakan e-learning tersebut.

\subsection{Perkembangan Fungsionalitas e-learning dan Spesifikasi Ideal}

Pengembangan sistem e-learning telah beberapa kali dikembangkan, sejatinya sistem e-learning semakin hari semakin memiliki banyak fungsi. Gambar.1 merupakan pertumbuhan pengembangan fungsi e-learning. Awalnya sistem e-learning hanya menempatkan konten pembelajaran di Internet saja agar dapat diakses oleh peserta didik kapan saja dan dimana saja. Kemudian fungsinya diperluas untuk memungkinkan sesi belajar yang akan dilakukan kapan saja dan dimana saja secara real-time antar user (mecakup instruktur dan peserta didik). Kini, e-learning 
JURNAL MEDIA INFORMATIKA BUDIDARMA

Volume 4, Nomor 2, April 2020, Page 309-317

ISSN 2614-5278 (media cetak), ISSN 2548-8368 (media online)

Available Online at https://ejurnal.stmik-budidarma.ac.id/index.php/mib

DOI 10.30865/mib.v4i2.1934

dapat memungkinkan untuk melakukan aktivitas pendaftaran, penilaian, dan posting sertifikasi kelulusan secara online. Dengan maksud menambah fleksibilitas, saat ini mobile learning telah diperkenalkan meskipun saat ini penggunaan terbatas dan belum dimanfaatkan secara maksimal. Sebagai sebuah fungsi, e-learning terus tumbuh sehingga lingkungan e-learning rentan terhadap serangan sehingga perlu adanya keamanan jaringan. Artinya, dengan fungsi yang semakin banyak membuat e-learning menjadi sistem yang lebih terbuka serta mudah atau rentan terkena ancaman keamanan. Menurut M.A. Helmiawan [5], suatu sistem e-learning harus memenuhi beberapa kategori diantaranya dijabarkan sebagai berikut:

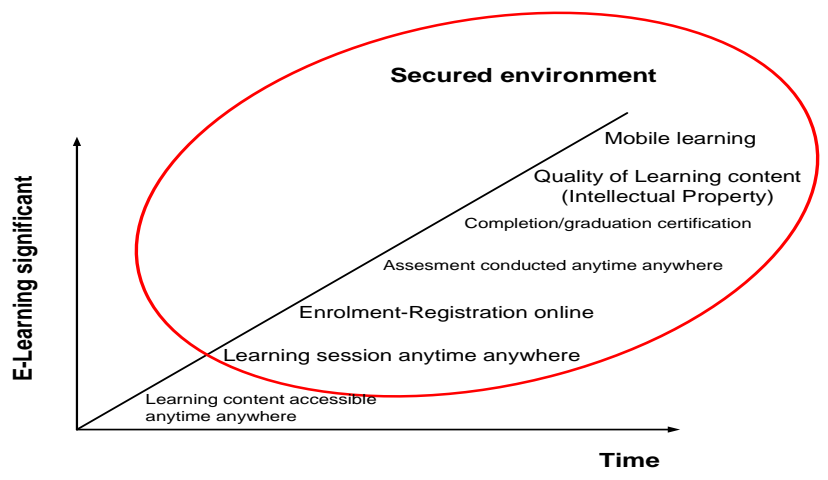

Gambar 1. Pertumbuhan fungsi e-learning, direproduksi dari [7].

1. Akses ke sistem e-learning harus terjaga secara rahasia dari akses luar yang mungkin tendensi ilegal. Disamping itu, identitas user juga harus terjaga kerahasiaannya

2. Pada sistem kontrol dijelaskan bahwa hanya user yang teregistrasi pada sistem e-learning yang dapat melakukan akses, dalam hal melakukan aktivitas pengunduhan materi, mengikuti ujian dan menipulasi data user itu sendiri. Pengaturan kontrol akses terhadap user dan komponen sistem e-learning harus ada.

3. Melakukan pengaturan terhadap database, dalam hal ini adalah proses manipulasi data hanya dapat dilakukan oleh user yang legal terhadap sistem

4. Berkaitan dengan pertanggungjawaban atau kebenaran data, yakni melakukan history terhadap aktifitas yang terjadi pada sistem

5. Sistem keamanan harus dapat dilakukan pengelolaan dan tidak mengganggu terhadap kinerja sistem. Ketersediaan sistem untuk melakukan autentikasi terhadap akses user, serta menghilangkan risiko terhadap aktifitas yang dapat merusak sistem

6. Sistem harus dapat melakukan autentifikasi yang baik

\subsection{Arsitektur Sistem online e-learning}

E-learning yang dibahas pada paper ini adalah sistem yang dapat digunakan untuk mengelola perkuliahan online yang dapat diakses melalui website (Internet). E-learning menjadi pilihan banyak kalangan untuk melakukan aktivitas pembelajaran dengan metode blended learning [16]. Secara umum sistem e-learning terdiri atas dua bagian, yaitu sistem hardware dan website interface. Bagian website interface dapat berbentuk website ataupun software aplikasi yang dapat digunakan oleh user, baik itu peserta didik ataupun tutor agar dapat berinteraksi secara langsung atau tidak langsung. Bagian kedua adalah hardware yang secara umum arsitekturnya ditunjukan oleh Gambar 2.

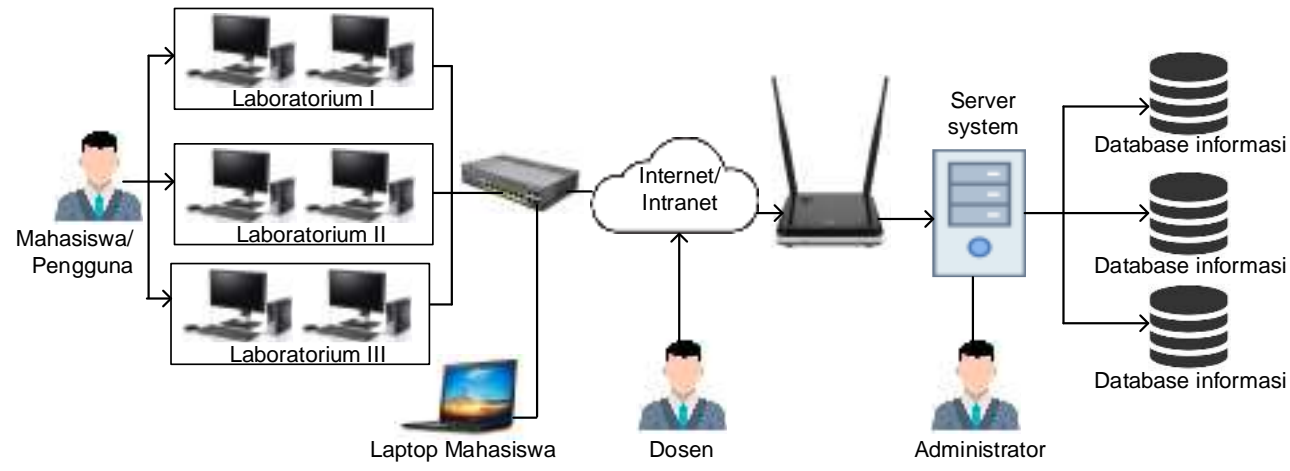

Gambar 2. Arsitektur Sistem e-learning, direproduksi dari [5] 
Dari Gambar 2 dapat dilihat bahwa dalam sistem e-learning terdapat beberapa bagian diantaranya adalah server yang terhubung langsung dengan website server dan berfungsi sebagai database. Bagian ini dikelola oleh administrator, infrastruktur jaringan LAN dan Internet yang diperlukan untuk mengakses sistem perkuliahan online. Dilain hal, juga diperlukan adanya koneksi LAN dan Internet yang memungkinkan akses server dari luar dam juga ketersediaan komputer klien, baik itu di lingkungan pendidikan seperti laboratorium ataupun diluar laboratorium.

\subsection{Standar Keamanan Informasi Pada Sistem e-learning}

Menurut H.F. Aldheleai, dkk [17], standar keamanan informasi pada sistem e-learning mencakup enam hal diantaranya yaitu:

a) Identifikasi, adalah proses penentuan user yang mencoba untuk login ke dalam sistem dimana hanya user yang tertentu yang berhak untuk mengakses. Pada kasus ini tentunya yang bertindak sebagai user adalah peserta didik dan tutor.

b) Otorisasi, adalah proses bagaimana membedakan dan menentukan antara user yang sudah dikonfirmasi ini memiliki hak atau hak istimewa, dimana kewenangan akun ini sesuai dengan porsi yang dibutuhkan untuk mengakses layanan ini, dalam hal ini berkaitan dengan kewenangan antara peserta didik, tutor, dan administrator.

c) Kerahasiaan, sistem e-learning yang memiliki banyak user di mana user dapat menjadi tamu, pelajar, tutor, dan administrator yang memiliki hak untuk mengakses database dan kerahasiaan user sistem ini dapat di pertanggungjawabkan.

d) Integritas, faktor utama dalam integritas adalah kontrol akses. User hanya berwenang untuk mengakses dan memperbarui isi data dan tidak ada upaya ilegal untuk memodifikasi isi dan sistem.

e) Ketersediaan, adalah jaminan bahwa data informasi yang dapat diakses oleh user setiap saat di lokasi manapun kapanpun dibutuhkan untuk dilihat.

f) Non-denial, sistem dipastikan harus tidak terjadi penolakan layanan ini harus menjamin tidak ada penolakan masuk pada sistem disebabkan oleh banyak hal.

\subsection{Ancaman Serangan Pada Sistem e-learning}

Pada setiap serangan sistem informasi, pasti ada aset berharga yang ditargetkan oleh peretas dan harus dilindungi apabila kita tidak ingin aset itu diketahui oleh peretas, menurut H.F. Aldheleai, dkk [17], aset pada sistem $e$ learning yang biasanya ditargetkan oleh peretas diantaranya adalah sebagai berikut: 1) Konten atau data pada sistem E-learning; 2) Data Personal dari user; 3) Pesan yang dikirim atau diterima oleh user; 4) Network Connectivity; dan 5) Bandwidth.

Dari beberapa target yang diincar oleh peretas, Menurut C. Savulescu, dkk [1], ancaman paling serius dari sistem pembelajaran online adalah apabila target dapat dijebol oleh peretas, celah-celah yang berpotensi diantaranya sebagai berikut: 1) Worms, denial of service, dapat berupa sebuah pengiriman virus atau seranganserangan yang disengaja dari software Bug. Dapat berupa software yang malfungsi; 2) Spionase, aksi pengumpulan data pribadi; 3) vandalisme atau sabotase, perusakan informasi; 4) kegagalan peralatan atau hardware yang digunakan yang dapat menyebabkan kegagalan teknis; 5) Pelanggaran pembajakan hak cipta yang mengorbankan hak kekayaan intelektual (HKI); dan 6) Pemerasan untuk pengungkapan informasi.

Dari beberapa ancaman tersebut, kerentanan sistem informasi pada e-learning dapat dikategorikan menjadi tiga bagian, diantaranya adalah sebagai berikut:

a) Kerentanan Privasi pengguna, Bocornya privasi individu dapat memiliki dampak besar pada korban, yaitu menyebabkan kerusakan status sosial. Dalam e-learning, privasi user juga penting karena dapat menciptakan lingkungan yang tidak baik dalam situasi belajar mengajar. Karena apabila privasi user tidak aman maka dikhawatirkan akan terjadi pengungkapan informasi rahasia dari user melalui tindakan yang disengaja bahkan mengekspos data privasi user. Peretas dapat mengendus atau mencuri data dalam transit dan setelah mendapatkan data, mereka dapat menjual data tanpa izin dari user. Salah satu cara dari peretas untuk menyerang privasi user pada sistem e-learning yaitu menyerang melalui internet browser yang digunakan. Baru-baru ini, kode serangan untuk mengekspos privasi user pada Firefox 16 tersedia secara online di internet. Dengan menggunakan kode ini, peretas mudah untuk mengekspos informasi secara rinci tentang riwayat browsing dari user. Menurut [2], peretas hanya perlu sekitar 10 detik untuk mengungkapkan nama user, dan sangat mudah bagi mereka untuk memperluas dan mengekstrak informasi pribadi yang terkandung dalam URL dari situs-situs lain.

b) Kerentanan Konten, Salah satu isu penting dalam keamanan sistem e-learning adalah integritas dari konten. Kemampuan untuk mendeteksi perubahan isi dari data yang masuk ke sistem sangat penting, oleh karena itu autentikasi konten telah menjadi salah satu isu yang paling penting dalam e-learning. Namun, banyak sistem e-learning tidak memberikan perlindungan integritas konten dan juga tidak mempertimbangkan properti digital perlindungan HKI untuk konten e-learning. Akibatnya, user yang sah dari e-learning mudah melanggar HKI 
digital lainnya dengan melakukan posting atau menyebarluaskan konten e-learning, seperti file presentasi, video tutorial, software, modul, dan buku tanpa adanya otorisasi [2].

c) Kerentanan website, Sebagian besar sistem e-learning merupakan aplikasi berbasis website. Dengan demikian, sistem e-learning juga mewarisi semua kerentanan sistem informasi pada setiap aplikasi yang berbasis website tersebut. Ada beberapa penyebab mengapa aplikasi berbasis website ini rentan terhadap berbagai serangan diantaranya sebagai berikut: a) Tidak update patch keamanan web server, aplikasi website dan mesin pengembang; 2) pengembang e-learning kurang menerapkan sistem keamanan dalam script; dan kerentanan baru karena meningkatnya website interaktif. Disisi lain, aplikasi berbasis website (termasuk $e$ learning) rentan terhadap banyak serangan karena sisi gelap dari internet yang dapat dibedakan menjadi dua kelompok. Kelompok pertama adalah teknologi sentris dan kedua adalah teknologi nonsentris. Dalam hal teknologi sentris, peretas menggunakan teknologi dalam menyerang aplikasi berbasis website. Namun, peretas menggunakan "rekayasa social" dalam mengeksploitasi kelemahan pengguna untuk mengontrol aplikasi berbasis website. Selanjutnya, spam, malware, hacking, DOS, phishing, penipuan klik, dan pelanggaran HKI digital telah dikategorikan sebagai teknologi sentris. Selain itu, teknologi nonsentris termasuk aktivitas pencurian online, penipuan online, cyber bullying, menyebarkan informasi palsu, judi online ilegal, membantu kejahatan dan perilaku tercela lainnya di dunia digital [2]. Sysadmin, Audit, Network, Security (SANS) Institute menyebutkan sebanyak dua puluh lima kesalahan yang paling sering dialami perangkat lunak terutama pada sistem e-learning diantaranya adalah: 1) injeksi SQL mencapai 7\%; 2) Cross Site Scripting mencapai 39\%; 3) kebocoran informasi mencapai $32 \%$; 4) proteksi layer transport yang tidak cukup mencapai 4\%; 5) fingerprinting mencapai 4\%; dan Http response splitting mencapai 3\% [18], seperti ditunjukan Gambar 3. Sedangkan menurut jenis serangan terhadap aset e-learning, dapat dibagi menjadi dua kategori yaitu serangan aktif dan serangan pasif penjelasan dari jenis serangan itu adalah [17] serangan aktif dan serangan pasif seperti yang ditunjukkan pada Tabel 3. Serangan pasif merupakan bentuk melanggar kerahasiaan menggunakan beberapa cara intersepsi tetapi tidak menyebabkan kerusakan pada isi, jenis serangan ini diantaranya mengancam standar keamanan. Sementara serangan aktif sangat berbahaya karena dapat memodifikasi isi dan jaringan komputer.

Tabel 3. Tipe Serangan Pada Sistem e-learning

\begin{tabular}{|c|c|c|c|}
\hline \multicolumn{2}{|c|}{ Serangan Aktif } & \multicolumn{2}{|c|}{ Serangan Pasif } \\
\hline Integrity & Authentication & Availability & Confidentiality \\
\hline Malicious code attack & Brute force attacks & Denial-of-service & $\begin{array}{l}\text { Group session } \\
\text { eavesdropping }\end{array}$ \\
\hline Message injection & Dictionary attack & Node attacks & $\begin{array}{l}\text { Group session traffic } \\
\text { analysis }\end{array}$ \\
\hline Traffic modification & Login spoofing attacks & Link attacks & Group identity disclosure \\
\hline Traffic deletion & $\begin{array}{l}\text { Key management } \\
\text { attacks }\end{array}$ & Network attacks & \\
\hline Traffic rerouting & Replay attacks & & \\
\hline Traffic misdelivery-rerouti & Man-in-middle attacks & & \\
\hline Forgery attacks & $\begin{array}{l}\text { Session hijacking } \\
\text { attacks }\end{array}$ & & \\
\hline Stack overflow attacks & $\begin{array}{l}\text { Non-repudiation } \\
\text { attacks }\end{array}$ & & \\
\hline
\end{tabular}

\subsection{Penanganan Terhadap Kerentanan Serangan Sistem e-learning}

Seperti dibahas pada subbab sebelumnya bahwa kerentanan sistem informasi pada website e-learning kategorikan menjadi tiga kategori yaitu kerentanan user privacy, kerentanan konten, dan kerentanan web aplikasi, pada subbab ini akan dijelaskan mengenai penanganan yang dapat dilakukan untuk menghindari serangan dari tiga kategori tersebut:

a) Proteksi Privasi, Menurut H.F. Aldheleai, dkk [17], proteksi privasi user pada sistem e-learning memiliki tiga prinsip yaitu: 1) Autentifikasi, adalah cara untuk memverifikasi identitas user dengan mendapatkan semacam sertifikat. Jika sertifikat berlaku, maka proses otorisasi dimulai. Autentikasi dan proses otorisasi adalah langkah pertama yang perlu dilakukan untuk mengamankan lingkungan pembelajaran online. I-S. Fan, dkk [7], merekomendasikan langkah-langkah autentikasi untuk mengidentifikasi user. Proses autentikasi selalu mengarah ke proses otorisasi seperti yang ditunjukkan pada Gambar 3, Kemudian 2) Identifikasi, setelah mengamankan sistem kita dari serangan apapun dengan menerapkan proses authentikasi, maka mulai proses identity untuk mengetahui identitas dari pengguna, dan 3) Presence and continuous, untuk memastikan kehadiran seorang pelajar atau peserta didik baru untuk jangka waktu tertentu. Beberapa solusi lain juga diusulkan untuk mengatasi masalah keamanan pada sisi privasi user diantaranya dilaporkan oleh Kambourakis, dkk [19] yang mengusulkan agar user dari sistem e-learning menggunakan tanda tertentu untuk e-learning dan 
m-learning (pembelajaran jarak jauh menggunakan perangkat mobile). Sistem yang diusulkan memiliki empat domain, yaitu, klien, e-learning server, public key infrastructure (PKI) server, dan server untuk menjaga kepercayaan. Dalam skenario ini, autentikasi tradisional yang didasarkan pada nama user dan password telah diganti dengan autentikasi tanda yang unik. Selain itu dari literatur lain, S. Mandala, dkk [2] mengusulkan bahwa sistem privacy-enhancing identity management (PIM) terintegrasi ke dalam blues e-learning platform agar dapat meningkatkan keamanan pada sisi privasi user. Dengan Menggunakan PIM, user dimungkinkan untuk mengontrol informasi pribadi mereka sesuai dengan kebutuhan informasi untuk terbuka kepada orang lain. Dalam pendekatan ini, nama samaran telah digunakan dalam mengidentifikasi identitas parsial. Berbagai nama samaran dengan derajat yang berbeda dapat digunakan oleh user untuk berinteraksi dengan orang lain, misalnya: nama samaran peran digunakan untuk berinteraksi lagi user dengan peran yang sama, hubungan samaran adalah untuk berkomunikasi dengan pasangan komunikasi yang sama, dan nama samaran orang diimplementasikan untuk semua konteks.

b) Proteksi Konten, Penelitian tentang kerentanan konten pada sistem e-learning seperti di Sajjadi, dkk, [20] yang memanfaatkan Digital Right Management (DRM) pada Moodle e-learning. Selain itu, mereka juga memperkenalkan model agregasi konten untuk menentukan tingkat pangsa sumber belajar yang diakses online. Terdapat empat tingkatan dalam agregasi konten yaitu aset, learning object (LO), pelajaran, dan kursus. Aset adalah bentuk paling dasar dari sumber belajar. Sementara tingkat atas di agregasi konten saja, yang mengumpulkan beberapa pelajaran. Dalam penelitian ini, masing-masing LO akan dibatasi untuk peran DRM untuk melindunginya dari pelanggaran hak cipta.

c) Proteksi Aplikasi Web, S. Mandala, dkk [2] mengusulkan penggunaan firewall dan virtual private network (VPN) untuk menjamin kerahasiaan, integritas dan ketersediaan sistem e-learning. VPN telah digunakan untuk menyediakan akses aman secara jarak jauh untuk user dari sistem e-learning di luar kampus. Di sisi lain, firewall telah digunakan untuk menyaring semua lalu lintas jaringan (termasuk trafik dijamin dengan VPN) yang datang ke e-learning. Sebuah Perlindungan e-learning berdasarkan Intrusion Detection System (IDS) dibahas pada literatur ini disebut sistem perlindungan dengan Intrusion block System (IBS). IBS mempekerjakan mesin deteksi intrusi, yang mengevaluasi apakah jaringan trafik data yang datang ke dalam sistem e-learning data berbahaya atau tidak. Data kategori berbahaya akan diblokir dan laporan akan dihasilkan karena alasan ini. Mereka mengklaim bahwa IBS dapat mencegah lima serangan umum situs website, seperti yang dijabarkan pada Subbab 6.2. Selanjutnya, M. Serrhini, dkk [21] melakukan penelitian tentang keamanan pada sistem e-learning dengan cara meningkatkan keamanan website browser dengan aplikasi stand-alone elearning awareness.

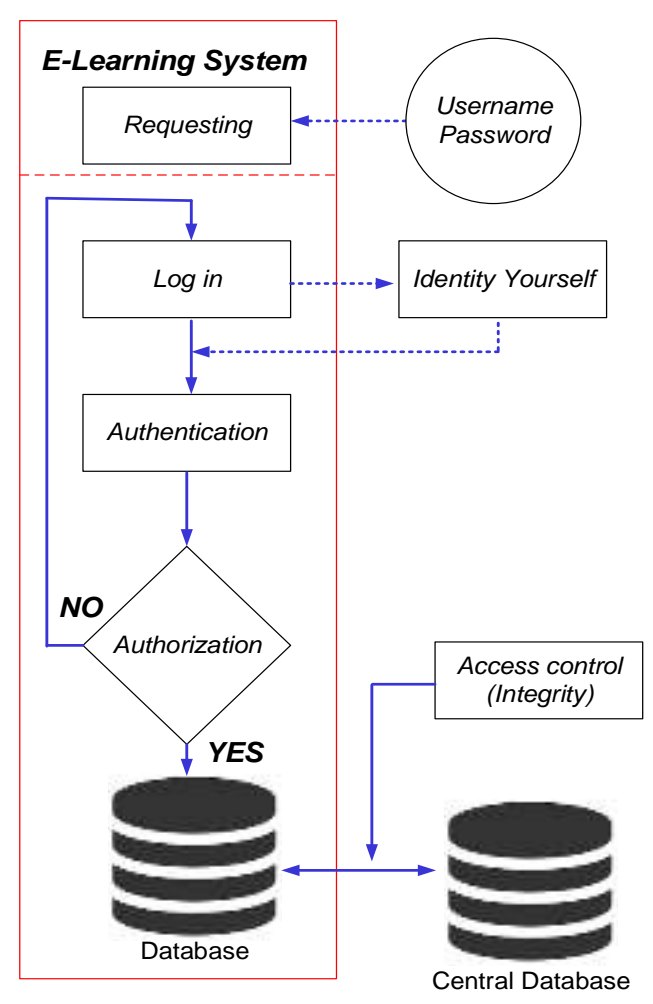

Gambar 3. Proses autentikasi, direproduksi dari [17] 


\subsection{Model Penerapan Keamanan Informasi Pada Sistem e-learning}

Terdapat beberapa contoh model keamanan yang dapat diterapkan pada sistem e-learning agar tidak mudak ditembus oleh peretas, sebagai contoh seperti yang diusulkan oleh S. Ahmed, dkk [22] diantaranya sebagai berikut:

a) Menggunakan mekanisme SMS, Pada model ini, sistem e-learning menghasilkan password khusus atau kata kunci ketika user akan melakukan $\log$ in, dan mengirimnya melalui pesan SMS pada nomor yang telah didaftarkan, selanjutnya user memasukan kata kunci tersebut untuk proses autentikasi.

b) Menggunakan Mekanisme Biometrics, Metode ini menggunakan ciri fisik yang unik untuk dapat melakukan autentikasi, sebagai contoh ciri fisik yang unik dan berbeda pada setiap orang adalah sidik jari, pada sistem ini semua user diwajibkan untuk mendaftar ciri-ciri fisik atau perilaku mereka, yang disimpan dalam database yang terenkripsi dari modifikasi.

c) Menggunakan Mekanisme Token, Metode ini menggunakan sistem autentikasi yang lebih ketat, yaitu dengan penggunaan token/smart card, sehingga untuk akses tertentu hanya bisa dilakukan oleh log in tertentu dengan menggunakan token khusus.

d) Menggunakan Mekanisme Digital Signature, Pada model ini, sistem e-learning menggunakan tanda tangan elektronik yang dapat digunakan untuk autentikasi identitas pengirim pesan atau penandatangan dokumen. Dan mungkin untuk memastikan bahwa konten asli dari pesan atau dokumen yang telah dikirim tidak berubah.

\section{KESIMPULAN}

Beberapa sisi pada sistem e-learning sering mengalami kerentanan keamanan, diantaranya adalah berhubungan dengan sisi privasi user atau bocornya privasi individu. Selanjutnya yaitu kerentanan integritas data pada konten, dan yang terakhir kerentanan pada sisi aplikasi website karena umumnya sistem e-learning merupakan aplikasi berbasis website. Jenis serangan yang dilakukan oleh peretas dapat dibagi menjadi dua jenis yaitu serangan aktif dan serangan pasif. Beberapa penanganan yang dapat dilakukan untuk membatasi serangan tersebut diantaranya apabila terjadi user privacy attacks, maka harus memperkuat proses autentikasi. Selanjutnya apabila terjadi serangan konten maka contoh penanganan yang dilakukan yaitu dengan menerapkan Digital Right Management (DRM) untuk melindungi konten dari pelanggaran HKI digital. Kemudian, apabila terjadi serangan aplikasi website maka harus memperkuat sisi keamanan website seperti penggunaan firewall dan VPN untuk menjamin kerahasiaan dan integritas pada sistem e-learning.

\section{REFERENCES}

[1] Savulescu C and Al E, 2015 Security in e-learning systems in Proc. of. Electronics, Computers and Artificial Intelligence Int. Conf. p. 19-24.

[2] Mandala S Abdullah A H and Ismail A S, 2013 A Survey of E-learning Security in Int. Conf. on ICT for Smart Society p. 1-6.

[3] Shuttleworth M, 2009, What is a Literature Review? [Online]. Available: https://explorable.com/what-is-aliterature-review. [Accessed: 10-Apr-2019].

[4] Majid H A and Al E, 2015 Investigation of Security Awareness on e-learning System Among Lecturers and Students in Higher Education Institution in Int. Conf. on Computer, Communication, and Control Technology (I4CT) p. 216-220.

[5] Helmiawan M A, 2018, Keamanan E-Learning Menggunakan Metode Square (Studi Kasus STMIK Sumedang), academia.edu. [Online]. Available: https://www.academia.edu/18056542/KEAMANAN_ELEARNING_MENGGUNAKAN_METODE_SQUARE . [Accessed: 23-Jan-2020].

[6] Ayodele T and Al. E, 2011 Towards E-learning Security: A Machine Learning Approach in Int. Conf. on Information Society (i-Society) p. 490-492.

[7] Alwi N H M and Fan I S, 2015 Information Security Management in E-learning in Int. Conf. for Internet Technology and Secured Transactions (ICITST) p. 767-770.

[8] Darmawan D Rian R Al and Herlandy P B, 2020 Game Edukasi Adventure Pengenalan Komponen Komputer Untuk Peserta Didik SMK Dar El Hikmah Pekanbaru EduTeach J. Edukasi dan Teknol. Pembelajaran 1, 1 p. 22-29.

[9] Bersin J, 2009, Modernize Corporate Training: The Enterprise Learning Framework, joshbersin.com. [Online]. Available: https://joshbersin.com/2009/05/modern-corporate-training-the-enterprise-learningframework/. [Accessed: 22-Dec-2019].

[10] Rochmah E and Majid N W A, 2018 Membangun virtual classroom melalui social learning networks (SLNS) Prem. Educ. J. Pendidik. Dasar dan Pembelajaran 8, 1 p. 15-21.

[11] Sholihah D A Shanti W N and Abdullah A A, 2019 Model Experiential Learning untuk Meningkatkan Kemampuan Berpikir Kritis Mahasiswa Pendidikan Matematika ION J. Ilm. Pendidik. Mat. 7, 3 p. 383-390.

[12] Sholihah D A and Shanti W N, 2017 Diposisi Berpikir Kritis Matematis Dalam Pembelajaran Menggunakan Metode Socrates J. Karya Pendidik. Mat. 4, 2 p. 1-9.

[13] Herlandy P B and Novalia M, 2019 Penerapan e-Learning pada Pembelajaran Komunikasi dalam Jaringan 
dengan Metode Blended learning Bagi Siswa SMK J. Educ. Inform. Technol. Sci. 1, 1 p. 24-33.

[14] Rahmawati F, 2016 E-Learning Implementation: Its Opportunities and Drawbacks Perceived by EFL Students J. Foreign Lang. Teach. Learn. 1, 1.

[15] Vitoria L Mislinawati M and Nurmasyitah N, 2018 Students' perceptions on the implementation of elearning: Helpful or unhelpful? IOP Conf. Ser. J. Phys. Conf. Ser. 1088.

[16] Majid N W A and Fuada S, 2020 E-Learning for Society: A Great Potential to Implement Education for All (EFA) Movement in Indonesia Int. J. Interact. Mob. Technol. 14, 2 p. 250-258.

[17] Aldheleai H F and Al E, 2015 User Security in E-learning System in Int. Conf. on Communication Systems and Network Technologies p. 767-770.

[18] Violettas G E Theodorou T L and Stephanides G C, 2013 E-learning Software Security Tested for Security Vulnerabilities \& Issues in Int. Conf. on e-learning p. $233-240$.

[19] Kambourakis G and Al. E, 2007 A PKI approach for deploying modern secure distributed e-learning and mlearning environments Comput. Educ. 48, 1 p. 1-16.

[20] Sajjadi Z Khodami A A and Modiri N, 2008 Learning Contents Integrity verification on E-learning Systems Using Digital Watermarking Technique in Int. Conf. on Information and Communication Technologies: From Theory to Applications p. 1-3.

[21] Serrhini M Dargham A and Moussa A A, 2012 Improve security of web Browser with stand-alone e-learning awareness application in Int. Conf. on Multimedia Computing and Systems p. $852-857$.

[22] Ahmed S Buragga K and Ramani A K, 2011 Security Issues Concern for E-learning by Saudi Universities in Int. Conf. on Advanced Communication Technology (ICACT) p. 1579 - 1582. 